\title{
MERLEAU-PONTY: A LITERATURA COMO PRODUTORA DE NOVAS SIGNIFICAÇÕES
}

\author{
MERLEAU-PONTY: \\ THE LITERATURE AS PRODUCER OF NEW SIGNIFICATIONS
}

\author{
Marcelo Vinicius Miranda Barros \\ Graduando em Psicologia, Universidade Estadual de Feira de Santana (UEFS), Departamento de \\ Ciências Humanas e Filosofia (DCHF), Feira de Santana, BA, Brasil.
}

\begin{abstract}
RESUMO: Partindo, principalmente, das obras a "A Prosa do Mundo" e a "Conversas - 1948", nas quais o filósofo Maurice Merleau-Ponty se debruçou quase que praticamente nas artes plásticas, nos fez sentir, então, a necessidade de direcionar mais o olhar desse filósofo para a literatura. A abordagem que Merleau-Ponty procurou para analisar as questões do fazer artístico foi os seus estudos sobre a linguagem. Assim, é através desses seus estudos que buscaremos nos aproximar da literatura, a fim de levantar pontos acerca da proximidade entre narrativa literária e filosofia, compreendendo a literatura, na sua forma-conteúdo, como produtora de novas significações, ações, pensamentos e não como um receptáculo de ideias.
\end{abstract}

PALAVRAS-CHAVE: Merleau-Ponty; Linguagem; Literatura; Filosofia; Forma-conteúdo.

\begin{abstract}
Starting, mainly, of his works "The Prose of the World" and "Conversations - 1948", in which the philosopher Maurice Merleau-Ponty leaned almost virtually in the plastic arts, made us feel, so, the need for direct more the look of this philosopher for literature. The approach that Merleau-Ponty sought to examine questions the artistic production was their studies on language. So, is through language what we seek to approach of the literature, in order to raise points about proximity between literary narrative and philosophy, comprising the literature, in form-content, as a producer of new significations, action, thought and not as a receptacle ideias.
\end{abstract}

KEYWORDS: Merleau-Ponty; Language; Literature; Philosophy; Form-content. 


\section{INTRODUÇÃO}

Quando se trata da relação entre a literatura e a filosofia, não se trata necessariamente de uma ser objeto de estudo da outra, de uma iluminar a outra, somente. O que se procura entender nessa relação é a capacidade que a literatura tem de ser um conhecimento próprio, produtora de saber, que dá a pensar. O que se entende é que há um remanejamento das hierarquias da área do conhecimento culminando em uma equivalência entre as duas, "de modo que tanto a literatura como a filosofia são, a partir de então, essencialmente produção e exposição de pensamento" (SILVA, 2009 , p. 327). Esse entendimento é o que buscaremos, principalmente, através do filósofo francês Maurice Merleau-Ponty, em seus escritos sobre a linguagem e sobre a forma-conteúdo na arte literária.

\section{A FORMA COMO REDE DE RELAÇÕES DE CONTEÚDOS E VICE-VERSA}

Merleau-Ponty afirma que a ciência clássica se baseia em uma distinção clara entre espaço e o mundo físico. O espaço é o meio homogêneo onde as coisas estão distribuídas em três dimensões (MERLEAU-PONTY, 2004), assim o filósofo continua dizendo que

existem muitos casos em que se observa as propriedades de um objeto mudarem com o seu deslocamento, por exemplo o peso, se transportamos o objeto do pólo ao equador, ou mesmo a forma, quando o aumento de temperatura deforma o sólido. Porém, justamente, essas mudanças de propriedades não são imputáveis ao próprio deslocamento, o espaço é o mesmo no equador, são as condições físicas de temperatura que variam aqui e ali, o domínio da geometria permanece rigorosamente distinto do domínio da física, a forma e o conteúdo do mundo não se mesclam (MERLEAU-PONTY, 2004, p. 10).

O que Merleau-Ponty busca afirmar é que o espaço físico é uma concepção da Física, enquanto ciência, e diz respeito ao meio que nos envolve. O espaço é uma estrutura ilimitada ou infinitamente grande, que contém todos os seres, que é definido por relações geométricas entre todos esses seres, e que é campo de todos os eventos. Portanto, as propriedades geométricas dos objetos permaneceriam as mesmas durante o seu deslocamento, se não fosse as condições físicas variáveis, nas quais os objetos são submetidos, segundo a ciência clássica (MERLEAU-PONTY, 2004).

O espaço é o mesmo do pólo ao equador e são as condições físicas que variam, que modificam os conteúdos, os objetos, no espaço, e, por isso, havendo essa distinção entre o espaço e o objeto, a forma e o conteúdo do mundo não se mesclam (MERLEAU-PONTY, 2004).

Mas, Merleau-Ponty vai dizer que tudo muda com as geometrias não euclidianas. Por exemplo, com e a partir do físico Albert Einstein, encontram-se usos para elas em teorias de física, como na "Teoria geral da relatividade", onde se pode interpretar que o espaço torna-se "curvo" na presença de campos gravitacionais (MERLEAU-PONTY, 2004).

Com a curvatura própria do espaço, as alterações dos objetos ocorrem devido ao seu deslocamento, devido a uma heterogeneidade das partes do espaço e de suas dimensões que "afetam os corpos que nele se deslocam com algumas transformações" (MERLEAU-PONTY, 2004, p. 11).

Deste modo, o mundo não é mais visto como que um objeto independente do espaço. Se o espaço é heterogêneo, e isso influi no objeto que nele se desloca, não há mais uma separação entre forma e conteúdo. Ou seja, 
temos um mundo em que os objetos não conseguiriam estar em identidade absoluta com eles mesmos, onde forma e conteúdo estão como que baralhados e mesclados, e que, por fim, não oferece mais essa estrutura rígida que lhe era fornecida pelo espaço homogêneo de Euclídes. Torna-se impossível distinguir rigorosamente o espaço das coisas no espaço, a ideia pura do espaço do espetáculo concreto que nossos sentidos nos oferecem (MERLEAU-PONTY, 2004, p. 11).

Para o filósofo, se torna impossível distinguir rigorosamente o espaço das coisas no espaço. Isso vai de acordo com o físico e o professor doutor Matsuura, na sua obra "Teoria da Relatividade" (2004), ao dizer que o conceito intuitivo de espaço nos vem da experiência da forma dos objetos e do volume ocupado por eles, bem como da experiência do deslocamento dos corpos no espaço. Apesar de invisível, o espaço parece existir como uma entidade objetiva e real. Nós mesmos nos sentimos ocupando lugar nele. Esse espaço pode ser medido e quantificado com uma régua ou trena (MATSUURA, 2004). Ou seja, podemos dizer que o conceito da forma nos vem da experiência dos conteúdos e vice-versa.

E se, segundo Matsuura, o espaço apesar de invisível se "materializa" devido aos objetos e volume ocupado por eles no próprio espaço, como visto aqui, a forma também, apesar de invisível e abstrata enquanto exclusivamente mental, pode materializar-se quando expressa (linguagem falada, escrita, mímica), especialmente, no nosso caso, quando expressa em literatura.

Quando Merleau-Ponty diz também que forma e conteúdo estão como que embaralhados e mesclados, o filósofo deixa claro que não se pode falar de espaço sem objeto, já que o espaço (que, na verdade, para ser mais preciso, seria espaço-tempo no Universo) contém coisas e abriga processos. Através do espaço, as coisas têm relações, não com o todo, mas entre si, de modo que a descrição do espaço (Universo) é uma descrição da rede de relações que ocorrem nele (MATSUURA, 2004). De tal modo, como o espaço, a descrição da forma é uma descrição da rede de relações de conteúdos que ocorrem nela. Ao se configurar uma relação de conteúdos se configura a forma, como também ao se configurar a forma se configura uma relação de conteúdos.

Se a descrição da forma é uma descrição da rede de relações de conteúdos que ocorrem nela, Merleau-Ponty vê a forma se afirmar no conteúdo e o conteúdo, ao mesmo tempo, se afirmar na forma. Assim, forma e conteúdo não se definem por si mesmos, pois a forma põe o conteúdo que a caracteriza como tal, e o conteúdo não se delimita senão como forma. O que há é forma-conteúdo (MERLEAU-PONTY, 2004).

O que temos é que, como na Ciência Física e nas percepções humanas sobre o espaço, o conteúdo e a forma não podem ser separados na literatura, na verdade conteúdo e forma é literatura. O conteúdo é linguagem, os personagens etc., e a forma é como se vai narrar esses personagens, como será expressa a linguagem, como a narrativa se dá. Salientando que não há separação entre o conteúdo e a forma, assim a linguagem já se apresenta como forma, o personagem já se desenrola como forma na história contada (MERLEAU-PONTY, 2004).

O filósofo francês Jean-Paul Sartre disse: "Laporte diz que caímos na abstração se pensamos em estado isolado aquilo que não foi feito para existir isoladamente" (SARTRE, 2012 p. 43). "Husserl também pensa assim: para ele, o vermelho é uma abstração, porque a cor não pode existir sem uma figura" (SARTRE, 2012 p. 43). Ou seja, é a "coisa" espaço-temporal com suas determinações todas é que é um concreto.

Seguindo esse ponto de vista sartreano, como analogia, a forma sozinha é abstrata, pois esconde uma "origem ontológica" no conteúdo, e, reciprocamente, o conteúdo sozinho é também abstrato, já que precisa "aparecer" à forma. O concreto é a totalidade sintética: forma-conteúdo (SARTRE, 2012).

E esse concreto, essa totalidade, se faz necessário para se compreender uma obra de arte, como a literatura. Segundo a Psicologia da Gestalt, 
em nenhuma época pode a obra de arte ser realizada ou compreendia por uma mente incapaz de conceber a integrada estrutura de um todo. Uma boa "Gestalt" não pode ser alterada sem que se altere a sua qualidade - numa obra prima de pintura, nenhuma linha, nenhuma forma, nenhuma cor pode ser alterada, sem depreciar a qualidade do quadro (FRACCAROLI, 1952, p.30).

Por isso, para que exista uma percepção propriamente Estética, é necessário ir à procura de uma ordem dentro do todo, ou, da forma-conteúdo (FRACCAROLI, 1952). De tal modo, através da forma-conteúdo, é que a literatura dá a pensar.

\title{
LITERATURA COMO PRODUTORA DE NOVAS SIGNIFICAÇÕES E NÃO COMO UM RECEPTÁCULO DE IDEIAS
}

Merleau-Ponty segue com esse seu discurso sobre a forma-conteúdo até chegarmos à sua afirmação de que nenhuma teoria pronta, nenhum dicionário anterior, pode falar sobre a obra em questão:

\begin{abstract}
decerto, quando defino uma mesa de acordo com o dicionário - prancha horizontal sustentada por três ou quatro suportes e sobre a qual se pode comer, escrever etc. - posso ter o sentimento de atingir como que a essência da mesa, e me desinteresso de todos os atributos que podem acompanhá-lo, forma dos pés, estilo das molduras etc., mas isto não é perceber, é definir. Quando, pelo contrário, percebo urna mesa, não me desinteresso da maneira como ela cumpre sua função de mesa, e o que me interessa é a maneira, a cada vez singular, com que ela sustenta seu tampo, e, o movimento único, desde os pés até o tampo, que ela opõe ao peso e que torna cada mesa distinta de todas as outras (MERLEAU PONTY, 2004, p. 56-57).
\end{abstract}

Dessa maneira, é preciso compreender a tal mesa como "a mesa" e não "uma mesa". Isso nos remete, como analogia, às artes: cada arte é uma arte, deve ser analisada na sua singularidade, na sua forma-conteúdo própria.

E por ser singular não se tem uma teoria pronta para definir uma literatura, por exemplo. Ela é mais produtora de novas significações do que recebedora destas, ou seja, ela não "comporta" uma teoria a priori, mas sim que uma teoria ou significados surgem na obra. E é por isso Merleau-Ponty diz que há uma diferenciação da tagarelice cotidiana da utilização poética da linguagem. A tagarelice só diz os nomes das coisas, para exprimir brevemente "do que se trata" (MERLEAU-PONTY, 2004). "Um romance bem-sucedido existe não como soma de ideias ou de teses, mas como uma coisa sensível [...] e que não deixa na lembrança um conjunto de ideias, mas antes um emblema e o monograma dessas ideias". Ou seja: é um possível, um terreno fértil, para que as ideias surjam.

A literatura, como um romance, é um terreno fértil que permite surgir ideias. Contudo, não se fala aqui somente de uma simples leitura dos fatos narrados, mas antes uma capacidade de criar novas significações, através de personagenssignificante-significados, se utilizando de uma linguagem própria, livre das regras gramaticais e da lógica corriqueira. Ao quebrar padrões, surge um novo mundo, novas ideias, novos significados. Nega-se as regras lógicas vigente, nega-se a linguagem formal, não com intuito de saber o que vem depois, nem sempre é assim, contudo com intuito de esperar o novo, aquilo que ainda não foi dito, pois não se fala apenas do que se sabe, mas também do que não se sabe, para sabê-lo ou a necessária "abertura às coisas sem significado" (MERLEAU-PONTY, 1964), que nos abre ao desconhecido em vez de confirmar aquilo que já conhecemos.

Por isso, "a comunicação em literatura não é simples apelo do escritor a significações que fazem parte a priori do espírito humano: estas, ao contrário, são suscitadas por um aprendizado ou por uma espécie de ação oblíqua" (MERLEAU-PONTY, 2012, p. 12). 
Se há uma espécie de negação da linguagem ordinária, Merleau-Ponty (2012, p. 12) afirma que "no escritor o pensamento não dirige de fora da linguagem: o escritor é ele mesmo um novo idioma que se constrói, que inventa meios de expressões e se diversifica segundo o seu próprio sentido".

É possível, então, entender a literatura como um sistema que permite dizer o que nunca foi dito. Essa possibilidade se vale de expressões existentes que recebem outras configurações, criando novos sentidos. O escritor é, como analogia, um alquimista das letras, das palavras, que permite a transmutação dos "metais inferiores ao ouro" ou das frases feitas às novas significações. De comportar o Elixir da Imortalidade, que é capaz de prolongar a uma obra literária, indefinidamente, assim que conseguisse realizar a chamada "Grande Obra de todos os Tempos", como diziam os alquimistas ao se referenciarem ao prolongamento indefinidamente da vida sagrada (HEDESAN, 2009). Portanto, Merleau-Ponty (2012, pp. 29-30) vai dizer que "é claro que não há somente frases feitas e que uma linguagem é capaz de assinalar o que ainda nunca foi visto". Mas como a linguagem tem essa capacidade, se o novo não fosse feito de elementos antigos, já expressos, se não fosse inteiramente definível pelo vocabulário e pelas relações sintáticas da língua em uso? A linguagem é capaz de compor qualquer significação nova a partir das antigas (MERLEAU-PONTY, 2012).

Contudo, é preciso ter cuidado com a comunicação: o sujeito a interpreta da forma que entende o mundo. Não pode compreendê-la através daquilo que é incognoscível para ele. Ou seja, jamais encontramos na literatura o que não projetamos de maneira refletida ou irrefletidamente. Como afirmou Merleau-Ponty (2012, p. 35): "em todo caso, jamais encontramos na fala dos outros senão o que nós mesmos pusemos, a comunicação é uma aparência, ela nada nos ensina de verdadeiramente novo". Então, o problema que fica é como a literatura pode nos trazer algo de novo, ter o que dizer, se já tem no nosso íntimo a sua significação, que pusemos nela?

Mesmo, isso, sendo uma questão, Merleau-Ponty ainda vai reforçá-la, por exemplo, dizendo que um telegrama que anuncia um desastre ao um sujeito não é absolutamente uma novidade; pois ele a recebe porque já sabia "que mortes e desastres são possíveis" (MERLEAU-PONTY, 2012, p. 36). E chega ao extremo desse pensamento ao dizer ainda que "compreendo o que me dizem porque sei de antemão o sentido das palavras que me dirigem, e enfim só compreendo o que já sabia, não me coloco outros problemas senão os que posso resolver" (MERLEAU-PONTY, 2012, p. 36).

Decerto, que só compreendo o que de alguma forma sei ou entendo, que faz parte do meu mundo ou do meu repertório. Mas, é aí que a literatura entra como um perigo que desfaz o comodismo da compreensão sobre o mundo:

o que há de arriscado na comunicação literária, o que há de ambíguo e de irredutível à tese em todas as grandes obras de arte, não é um defeito provisório da literatura do qual se pudesse esperar livrá-la, é o preço que se deve pagar para ter uma linguagem conquistadora, que não se limite a enunciar o que já sabíamos, mas nos introduza a experiências estranhas, a perspectivas que nunca serão as nossas, e nos desfaça enfim de nossos preconceitos (MERLEAU-PONTY, 2012, p. 157).

Por isso é que Merleau-Ponty afirma que a literatura não deve ser coberta de teoria a priori, mas que seja uma obra que permita o sujeito experenciá-la o que lhe é estranho, ambíguo e que o empenhe a rever o seu mundo, no qual se compreende só o que já sabia, pois a literatura não se limita a enunciar o que já sabíamos, mas nos introduzir as experiências forasteiras, criadoras de significações e de novas ideias, e não repetir o que já se conhece.

O que o filósofo expõe é que a literatura é como descobrir uma paisagem nova: "jamais veríamos uma paisagem nova se não tivéssemos, com nossos olhos, o meio de surpreender, de interrogar e de dar forma a configurações de espaço e de cor jamais vistas até então" (MERLEAU-PONTY, 2012, p. 157). 
Quando Merleau-Ponty assegura que a literatura é descobrir uma paisagem nova, entra em um entendimento, de certa forma, com o filósofo da arte Arthur Danto, o qual este diz que

a forma como a verdade, tal como eles a entenderam, deve ser compreendida, poderia requerer justamente uma forma de leitura, portanto um tipo de relação com aqueles textos, totalmente diferentes daqueles apropriados para um artigo (DANTO, 2014, p. 178).

Assim, equivale entender que o romance pode exigir uma forma de se fazer novas significações, conhecimentos que convencionalmente não eram possíveis, já que não só os escritores, como também os filósofos

com pensamentos realmente novos tiveram simplesmente que inventar novas formas para veiculá-los e que seja possível que, da perspectiva do formato padrão, nenhum caminho por essas outras formas - portanto, nenhum caminho por esses sistemas ou essas estruturas de pensamento - possa ser encontrado (DANTO, 2014, p. 180).

Dito de outra maneira, tanto a filosofia como a literatura precisa de uma "linguagem extra", se pretendem mostrar algo de novo no conhecimento.

É preciso também entender que se na literatura é como descobrir uma paisagem nova, nos ensaios filosóficos também apresentam algo parecido, que é não poder

[...] desconsiderar exatamente a maneira pela qual a filosofia funciona como funciona a literatura, não no sentido de artefatos verbais extravagantes, mas como um engajamento dos leitores na busca daquele tipo de universalidade que supus caracterizar a referência literária: como se tratasse do leitor no momento da leitura, por meio do processo da leitura. Nós os lemos como literatura nesse sentido porque, no esplêndido pensamento de Hegel, eles existem para o leitor, que está "neles desde o começo" (DANTO, 2014, p. 196).

Seguindo o filósofo Arthur Danto, os textos filosóficos implicam na variedade correspondente de tipos possíveis de leitores e, portanto, de teorias daquilo que somos na dimensão da leitura (DANTO, 2014). E assim, a professora Isabel Matos Dias entende que "a radicalidade da literatura e de toda a arte, como da própria filosofia, reside para o autor numa 'abertura às coisas sem conceito', na 'apresentação sem conceito do Ser universal'"' (DIAS, 1997, p.37), mas ela ainda alerta que

a radicalidade significa assim aconceptualidade, o que não deve interpretar-se como uma orientação para o irracional e o inconceptual, mas antes como uma exigência de alargamento e aprofundamento da racionalidade, a busca de uma racionalidade mais funda e integradora que não esconjure a própria dimensão mágica e onírica (DIAS, 1997, p. 38, grifo do autor).

Isabel Matos Dias deixa claro que não se trata de uma irracionalidade, mas de uma forma particular de ver a arte como produtora de novas significações. Ou seja, "quanto a literatura, em geral ela aceita mais resolutamente nunca ser total e dar-nos apenas significações abertas" (MERLEAU-PONTY, 2012, p. 186), já que não se fala apenas do que se sabe, mas também do que não se sabe para sabê-lo ou a necessária "abertura às coisas sem conceito" (MERLEAU-PONTY, 1964). E assim retomamos a capacidade da linguagem, dita anteriormente aqui, em ser capaz de compor qualquer significação nova a partir das antigas (MERLEAU-PONTY, 2012). Com outras palavras, quando o escritor recebeu a língua que escreverá, tudo ainda está por fazer. Assim, cada escritor sabe que a língua nos dá mais do que teríamos sabido encontrar por nós mesmo.

Portanto, será preciso chegar à idéia central, segundo a qual a literatura não apenas desperta em mim pensamentos já formados, como também me arrasta num movimento de pensamento, no "qual eu não teria sido capaz sozinho, e me abre finalmente para significações estranhas" (MERLEAU-PONTY, 2012, p. 198).

O que se entende aqui é que o filósofo busca aproximar a literatura com a filosofia, já que durante muito tempo a filosofia e a literatura existiram como técnicas diferentes, no que se refere a sua forma de expressão, como também uma diferença de objeto 
(MERLEAU-PONTY, 1947). Entretanto, tudo muda quando surge, na contemporaneidade, a filosofia fenomenológica e a filosofia existencial, por exemplo, que possuem intuito de não mais explicar o mundo, mas de experienciar o mundo, "um contato com o mundo, que precede a todo pensamento sobre o mundo" (MERLEAU-PONTY, 1947, p. 4, grifo do autor). Assim, segue ainda uma afirmação de Merleau-Ponty:

a tarefa da literatura e a da filosofia não podem mais, então, ser separadas. Quando se quer fazer falar a experiência do mundo, e de mostrar como a consciência faz a evasão do mundo, não se pode mais pretender uma transparência perfeita de expressão. A expressão filosófica adquire a mesma ambiguidade da expressão literária, desde que o mundo é feito de tal maneira que não pode ser expresso senão por "histórias" (MERLEAU-PONTY, 1947, p. 4).

Quando se diz que queremos fazer falar sobre a experiência do mundo e de mostrar como a consciência faz a evasão do mundo, não podendo mais pretender uma transparência perfeita de expressão, o filósofo francês condiz com uma afirmação, citada anteriormente aqui, de Arthur Danto, quando este diz que com pensamentos realmente novos, filósofos, escritores tiveram simplesmente que inventar novas formas para veiculá-los, se afastando da perspectiva diferente do formato padrão, como um artigo, ou seja, reinventando a forma-conteúdo dos escritos (DANTO, 2014).

Além do mais, se um contato com o mundo precede a todo pensamento sobre o mundo (MERLEAU-PONTY, 1947), é porque as frases feitas perdem sua força perante a arte literária, mas a linguagem, como forma-conteúdo, é capaz de assinalar o que ainda nunca foi visto. A literatura, então, não se limita a proclamar o que já conhecemos, mas nos introduzir as experiências criadoras de novas significações, onde o pensar só existe depois da ação. A ação aparece como o primeiro princípio das narrativas literárias, a partir das quais as demais noções se sobrepõem. Portanto, inserir uma teoria antes de uma narrativa, faz da literatura um receptáculo de ideias e não um sistema que gera tal teoria (MERLEAU-PONTY, 1947).

Assim, os romances literários podem ser visto como literatura-como-filosofia, devido ao aparecimento de formas híbridas de expressão, "embora não empreguem uma só palavra do vocabulário filosófico" (MERLEAU-PONTY, 1947, p. 4). Contudo, não se pode confundir esse tipo de literatura filosófica com aquela literatura "moral". Será, então, uma literatura amoral que interessa, porque não procura dizer ou acreditar em uma natureza humana, a qual passa por costumes antigos, culturais que se dissolvem com a intervenção de uma filosofia (MERLEAU-PONTY, 1947), já que "muitas vezes em choque com os padrões morais estabelecidos, a Arte leva-nos a pressentir novas possibilidades valorativas" (NUNES, 2000, p.89).

Isso não exclui, entretanto, da literatura e da arte em geral, a finalidade ética, pois "a verdade é que o desinteresse da Arte não é indiferença pelo humano, nem a sua aparência ilusão pura ou completo afastamento da realidade" (NUNES, 2000, p.89), pelo contrário, a arte amoral, desinteressada, é menos unilateral, sendo mais abrangente ou, como visto, é uma abertura às coisas sem significados. Ou, ainda, é sendo, "como diz Jean-Paul Sartre, inclusiva, que ela pode revelar-nos, na transparência do mundo criado pelo artista, as possibilidades latentes do ser humano, e dar-nos uma visão mais íntegra e compreensiva da realidade" (NUNES, 2000, p.89).

Dita com outras palavras, o começo de uma literatura filosófica é o fim de uma literatura "moral" que possui uma forma-conteúdo impregnada de tagarelice cotidiana em detrimento da utilização poética da linguagem (MERLEAU-PONTY, 1947). Em suma, é revelando as possibilidades de consciência moral e não adotando uma moral, que a arte cumpre a sua finalidade ética, filosófica, ou seja, a arte leva-nos, por exemplo, à literatura como produtora de novas significações.

Correspondência: Marcelo Vinicius Miranda Barros. Universidade Estadual de Feira de Santana, Av. Transnordestina, s/n, Novo Horizonte, CEP: 44036-900, Feira de Santana, BA, Brasil. E-mail: marcelovmb@gmail.com Conflito de interesses: Nenhum.

Todos os autores leram e aprovam a versão final submetida a revista Em curso. 


\section{Bibliografia}

DANTO, A. O descredenciamento filosófico da arte. Tradução: Rodrigo Duarte. São Paulo: Autêntica, 2014.

DIAS, M, I. Vestígio do Mundo. Literatura e filosofia em Merleau-Ponty. Philosophica 10, Universidade de Lisboa, Lisboa, pp. 29-44, 1997.

FRACCAROLI, C. A percepção da forma e sua relação com o fenômeno artístico: o problema visto através da Gestalt (Psicologia da Forma). USP. São Paulo: FAU, 1952.

MATSUURA, T, O. Teoria da Relatividade. Coleção: Para Saber Mais. São Paulo: Abril, 2004.

MERLEAU-PONTY, M. A Prosa do Mundo. Tradução: Paulo Neves. São Paulo: Cosac Naify, 2012.

MERLEAU-PONTY, M. Conversas - 1948. Tradução: Fábio Landa e Eva Landa. São Paulo: Martins Fontes, 2004.

MERLEAU-PONTY, M. Romance e Metafísica. In: Revista Joaquim nº 14. Curitiba, p. 4, 1947.

MERLEAU-PONTY, M. L'oeil et 1'esprit, Paris: Gallimard, 1964.

NUNES, B. Introdução à Filosofia da Arte. 5. ed. São Paulo: Editora Ática, 2000.

SARTRE, J-P. O Ser e O Nada: Ensaio De Ontologia Fenomenológica. Edição 21, Petrópolis: Editora Vozes, 2012.

SILVA, A, A. Literatura e filosofia: entre as razões do sentimento e os prazeres da inteligência. Estudos Avançados. vol.23, n 66, São Paulo, 2009. 